Electronic supporting information for:

\title{
The Solvatochromism Study of DCM \\ Encapsulated in ZIF-90 and The Potential Application of DCM/ZIF-90 as the Fluorescence Down-Conversion Layer for LED chip
}

Hung-Ying Chen and Chih-Wei Chang*

Department of Chemistry, National Changhua University of Education, Taiwan *Corresponding author: cwchang@cc.edu.tw 

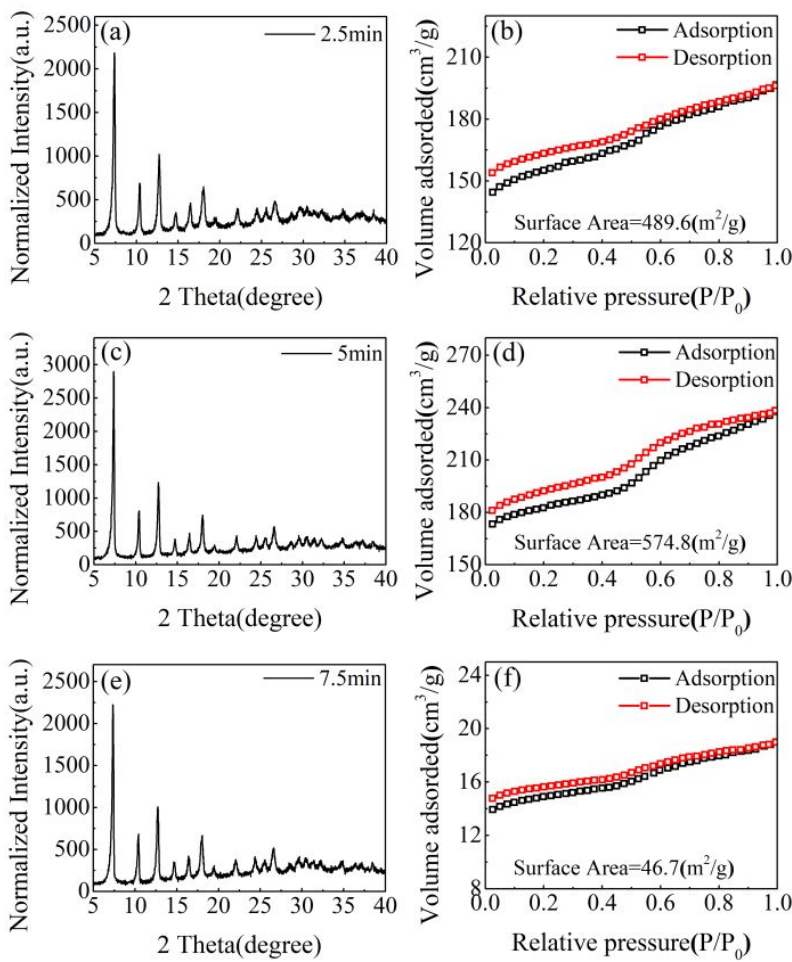

Figure S1: The PXRD spectra of the ZIF-90 reacted for (a) 2.5 minutes (c) 5 minutes (e) 7.5 minutes. The $\mathrm{N}_{2}$ adsorption-desorption isotherm of the ZIF-90 reacted for (b) 2.5 minutes (d) 5 minutes (f) 7.5 minutes. 

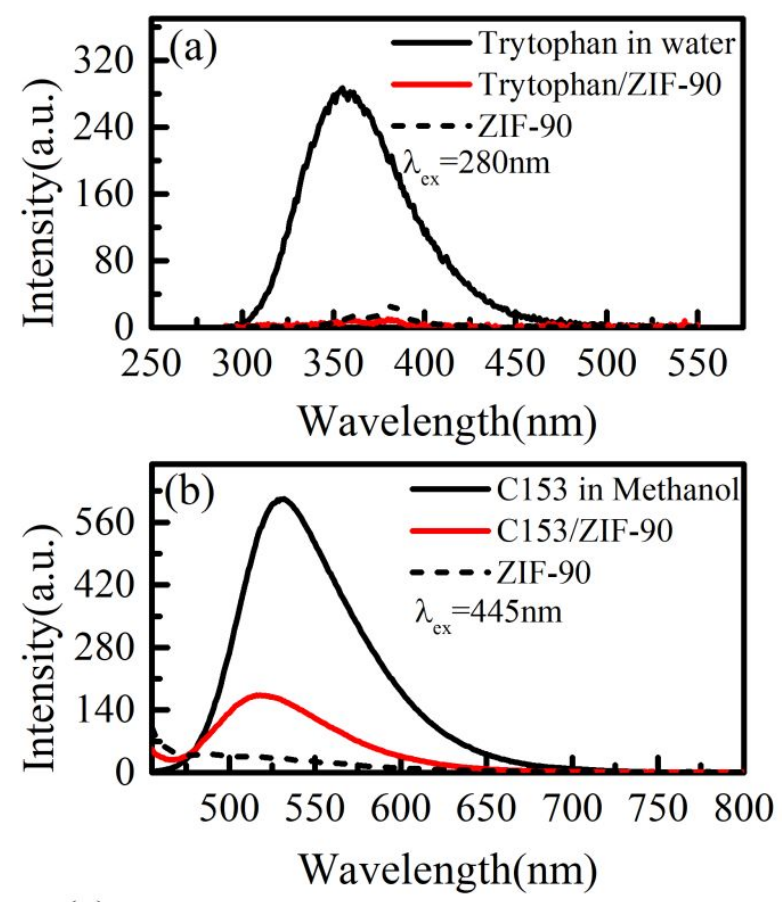

(c)

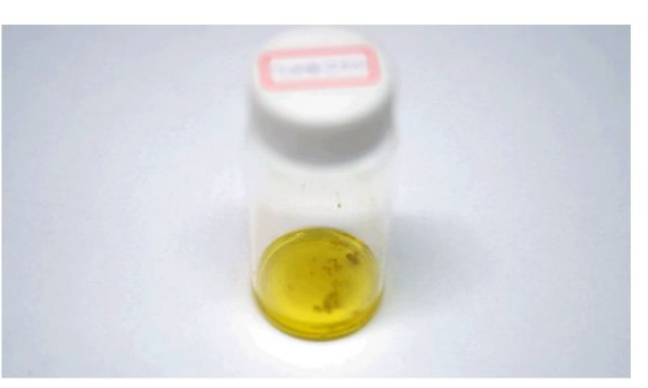

Figure S2: (a) The emission spectra of the tryptophan and the tryptophan/ZIF-90 in water. (c) The emission spectra of the coumarin 153 and the coumarin 153/ZIF-90 in methanol solution. (c) The precipitate formed by the coumarin 153 and ICA in methanol soluiton. 

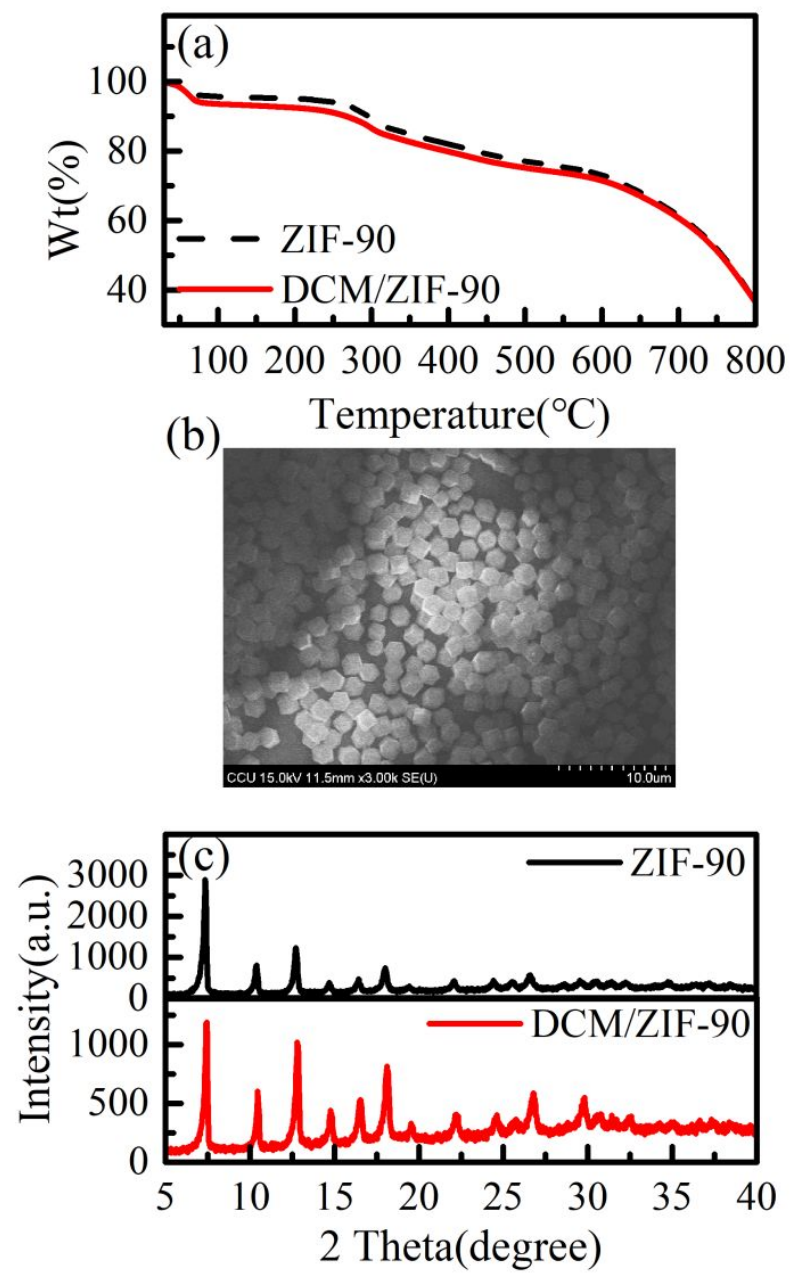

Figure S3: (a) The comparsion between the TGA curves of the ZIF-90 and DCM/ZIF-90. (b) The TEM image of the DCM/ZIF-90. (c) The comparsion between the PXRD spectra of the ZIF-90 and DCM/ZIF-90. 


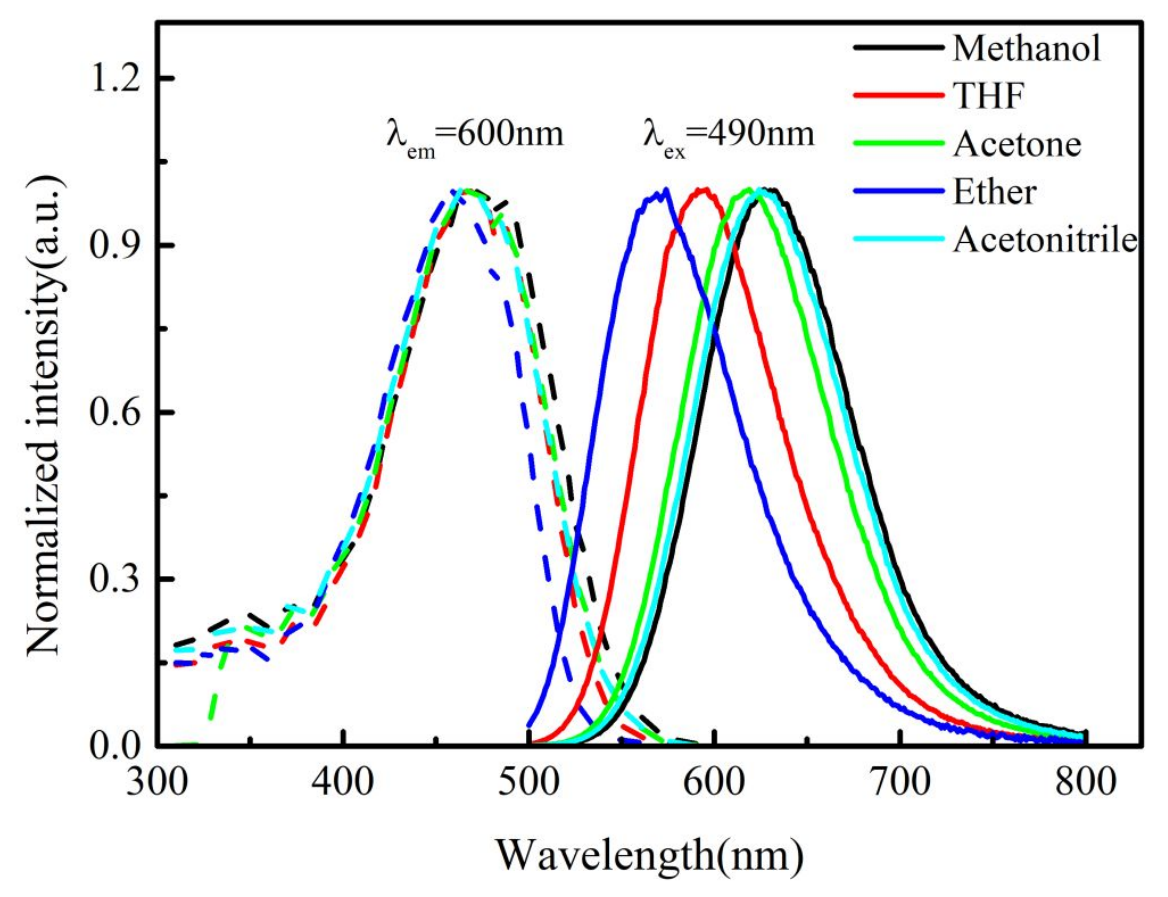

Figure S4: The steady state excitation (dash line) and emission (solid line) of the DCM in various solutions. 

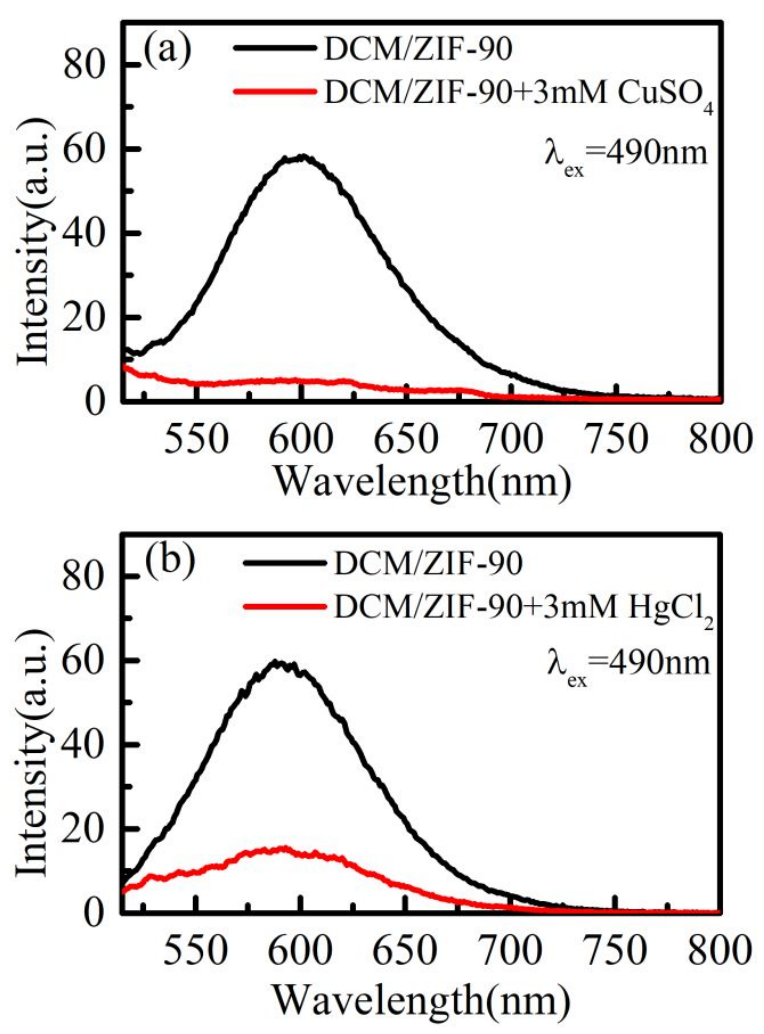

Figure S5: The emission spectra of the DCM/ZIF-90 in (a) $\mathrm{CuSO}_{4}$ and (b) $\mathrm{HgCl}_{2}$ aqueous solution. 

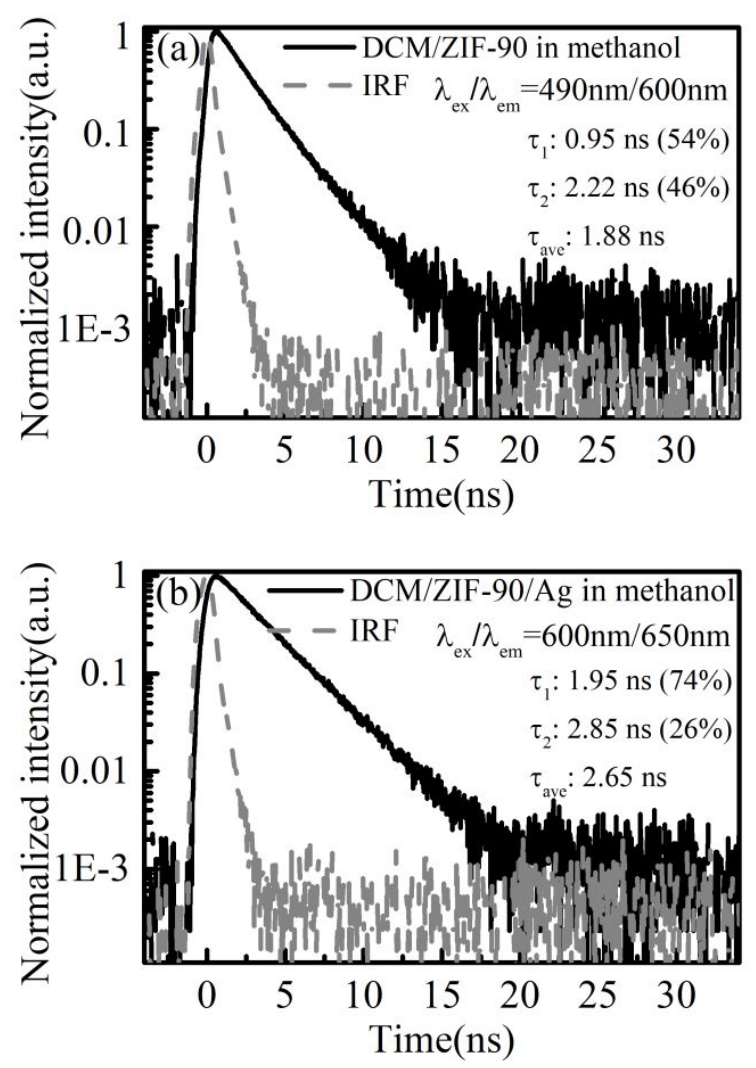

Figure S6: The fluorescence decay dynamics of (a) the DCM/ZIF-90 and (b) the DCM/ZIF-90/Ag in methanol solution. 